Article

\title{
Child Labor Trafficking in the United States: A Hidden Crime
}

\author{
Katherine Kaufka Walts \\ Center for the Human Rights of Children, Loyola University Chicago, 60660 Chicago, USA; E-Mail: kkaufkawalts@luc.edu
}

Submitted: 10 February 2017 | Accepted: 24 March 2017 | Published: 23 June 2017

\begin{abstract}
Emerging research brings more attention to labor trafficking in the United States. However, very few efforts have been made to better understand or respond to labor trafficking of minors. Cases of children forced to work as domestic servants, in factories, restaurants, peddling candy or other goods, or on farms may not automatically elicit suspicion from an outside observer as compared to a child providing sexual services for money. In contrast to sex trafficking, labor trafficking is often tied to formal economies and industries, which often makes it more difficult to distinguish from "legitimate" work, including among adolescents. This article seeks to provide examples of documented cases of child labor trafficking in the United States, and to provide an overview of systemic gaps in law, policy, data collection, research, and practice. These areas are currently overwhelmingly focused on sex trafficking, which undermines the policy intentions of the Trafficking Victims Protection Act (2000), the seminal statute criminalizing sex and labor trafficking in the United States, its subsequent reauthorizations, and international laws and protocols addressing human trafficking.
\end{abstract}

\section{Keywords}

adolescent; child; child trafficking; crime; human trafficking; labor trafficking; involuntary servitude; USA

\section{Issue}

This article is part of the issue "Perspectives on Human Trafficking and Modern Forms of Slavery", edited by Siddharth Kara (Harvard Kennedy School, USA).

(C) 2017 by the author; licensee Cogitatio (Lisbon, Portugal). This article is licensed under a Creative Commons Attribution 4.0 International License (CC BY).

\section{Introduction}

Human trafficking has received international and domestic attention as a "growing problem," when in fact, the exploitation of people has been an unfortunate reality for ages. In the United States, the term "human trafficking" has been codified under the adoption of the Protocol to Prevent, Suppress and Punish Trafficking in Persons, especially Women and Children (Palermo Protocol) (2000) and the Trafficking Victims Protection Act (TVPA) of 2000 and its subsequent reauthorizations (2003, 2005, 2008, 2013). The policy intentions of the TVPA, in parallel to the United Nations' Palermo protocol, are to protect victims, to prosecute perpetrators, and to prevent both labor and sex trafficking of all persons, including children and adults, citizens and foreign nationals. The TVPA created new crimes to help prosecute perpetrators under the United States federal criminal code, including "forced labor," "trafficking with respect to peonage, slavery, involuntary servitude, or forced labor," and "sex trafficking of children, or by force, fraud or coercion." These new statutes attempt to expand anti-slavery statutes, particularly involuntary servitude (Sale into Involuntary Servitude, 1948), and include a broader range of tactics perpetrators use to compel and coerce individuals to perform labor or services, including sexual services. Most notably, the TVPA expands previous interpretations of coercion to include physical harm, but also psychological and financial harm. These tactics can include psychological manipulation, deceit, trickery, false information, financial exploitation, and abuse of the legal process. This legislation also provides various mechanisms to protect victims through appropriation of funds for specialized services for victims, protections under criminal and immigration systems for victims, immigration relief for undocumented victims, as well as appropriations for research to better understand the dynamics of human trafficking in the United States. All states in the United States have passed similar laws, criminalizing both sex and labor trafficking. 
The challenges of identifying prevalence estimates of human trafficking, both sex and labor, are well documented (Finklea, Fernandes-Alcantara, \& Siskin, 2015; Stransky \& Finkelhor, 2008), and estimates measuring occurrences of human trafficking in the United States vary substantially (Gibbs, Hardison Walters, Lutnick, Miller, \& Kulckman, 2015; Goodey, 2008). The Polaris Project, which manages the National Human Trafficking Resource Center Hotline (NHTRC) as part of a partnership with the United States government, reports that in 2015, 5,973 cases of human trafficking were reported. The majority of calls to the NHTRC over the last five years continue to be for sex trafficking, with $33 \%$ of all sex trafficking reported cases made to the hotline involved children versus $16 \%$ of labor trafficking reported cases involving children. Between December 2008 and March 2017, 1,090 cases of labor trafficking involving at least one minor have been reported to the NHTRC, indicating $20 \%$ of labor trafficking cases reported to the NHTRC since it began operating involved minors (E. Gerrior, personal communication, May 15, 2017).

While the United States anti-trafficking statutes have codified crimes of both sex and labor trafficking, sex trafficking continues to dominate the narrative of human trafficking in the United States, particularly around children. Sex trafficking investigations and prosecutions of children continue to outnumber trafficking of children for labor (Bureau of Democracy, Human Rights, and Labor, 2016). One cannot presume that tips, investigations, or prosecutions alone reflect actual cases. The long history of various forms of labor exploitation, including indentured servitude, involuntary servitude, debt bondage, and more recently, labor trafficking cases in the United States demonstrate that these cases, in fact, do exist, and that there may be other reasons for the lack of identification, reporting, investigations, and prosecutions of such cases. Additionally, there is a clear contrast in the numbers of cases reported by governmental and public agencies, versus non-governmental organizations that needs to be explored. In a 2011 study, nongovernmental organizations reported identifying more labor cases, with $64 \%$ of the victims served being victims of labor trafficking, and $10 \%$ as victims of both labor and sex trafficking. Law enforcement, in contrast, the same year reported identifying $83 \%$ of their caseload as sex trafficking cases (Banks \& Kyckelhahn, 2011).

There have been an increasing number of legislative bills and initiatives introduced to combat human trafficking, primarily targeting the sex trafficking of United States citizen youth. The bills address financing services for youth who are trafficked, increase enforcement measures against those who purchase sex from children and teenagers, and ensure that youth who are purchased don't find themselves penalized, and instead are treated as victims. These are all worthy and promising measures, but all ignore the plight of children who are trafficked for labor in the United States. The dearth of research and measures to identify child labor trafficking will likely have an effect of undermining efforts to respond to child labor trafficking occurring in the United States. This article seeks to provide context of the plight of child labor trafficking victims in the United States by first providing an overview and examples of child labor trafficking cases in the United States. It then addresses the deficiencies in policy, data collection, and research addressing the phenomenon of child labor trafficking, and concludes with recommendations of how to better protect and respond to child labor trafficking victims in the United Sates. While the article focuses exclusively on the experiences of the United States, the observations, discussion, and recommendations may be helpful to other parts of the world.

\section{Who Are Child Labor Trafficking Victims in the United States?}

\subsection{Brief History of Child Labor Exploitation and Trafficking}

There is a long, unfortunate historical legacy of children (boys and girls) being exploited for labor in the United States. In early American history, much labor was organized under a system of bonded labor known as indentured servitude. This typically lasted for several years, and it was often a means of using labor to pay the costs of transporting people-including large numbers of children and youth from England northern Europe-to the thirteen colonies of the early Untied States. An indentured servant was a worker under contract to an employer for a fixed period of time, typically 4-7 years, in exchange for their transportation, food, clothing, lodging and other necessities. The mortality rates for these servants were very high. Their periods of indenture were often extended for various reasons, such as fines and costs in association with "maintenance" (food, shelter, etc.; Mintz, 2006). By the 18th century, courts and legislatures racialized slavery to apply nearly exclusively to Black Africans and people of African descent, and occasionally to Native Americans. Young people, alongside adults, toiled in the fields and inside homes as domestic slaves. In 1862, President Abraham Lincoln issued the "Emancipation Proclamation" executive order, which was followed by the adoption of the $13^{\text {th }}$ Amendment in 1865 , officially abolishing and prohibiting slavery and involuntary servitude.

Case law and policy grappling with the definition of involuntary servitude post- $13^{\text {th }}$ Amendment in the United States demonstrates that children were not immune to labor exploitation and forms of slavery. One of the earliest examples were the practices of padrones during the early $18^{\text {th }}$ century. The padrones were men who lured young boys away from their families, brought them to large cities in the United States, and put them to work for their personal profit. These children were stranded in large, cities in a foreign country, and given no education or other assistance toward self-sufficiency. Without such assistance, without family, and without other sources of 
support, these children had no choice but to work for their masters or risk physical harm. In one of the early cases addressing this practice of exploiting children for personal profit, United States v. Ancarola (1880), Ancarola traveled to Italy, tricked parents with false statements promising a better life, and persuaded them to send their children to the United States. He subsequently held seven boys, ages 11-13, in confinement in New York City and subjected them to compelled labor of begging and playing musical instruments. The court found that there was evidence that the intention of Ancarola was to employ the children as beggars or street musicians, "for his own profit," "to the injury of their morals, subject to his control," and they could not properly be considered rendering him "voluntary service." The court also stated that these children were incapable of exercising will or choice affirmatively on the subject. In 1874, Congress enacted a resolution, known as the "Padrone statute" "to prevent [this] practice of enslaving, buying, selling, or using Italian children" (Sale into Involuntary Servitude, 1948, 18 U.S.C. § 446). While most notable cases in the United States involving padrones were Italian, youth from other countries, including Greece, China, Japan, and Mexico, were also recruited and exploited in the United States under similar tactics.

Children forced to work in homes as domestic servants and on farms in agriculture continued to exist, even in the post-chattel slavery era. In the formative involuntary servitude case United States v. Lewis (1986), all of the defendants named belong to a cult named the "House of Judah." As part of the rules of the cult, corporal punishment was deemed "proper and necessary." The House of Judah organized a compound in Western Michigan, which included a farm. At the compound, children were not allowed to attend public school, and could only attend school at camp and forced to work on the compound and follow strict rules, with guards patrolling the perimeter of the camp. There were incidents in which children were burned as punishment, and beatings were common for those who tried to run away or didn't do assigned work. Boys as young as 8 or 9 were severely beaten, and at least one boy was beaten to death. The schoolteacher was beaten and forced to show her wounds to the students, as were parents. Defendants argued that children living with parents could not become the slaves of someone else, that they were in the care and the "property" of their parents and could not therefore become the "property" of others. The court ultimately held that due to the "pervasive climate of fear" existing in the camp, including children forced to watch their parents and teacher shamed and abused, the children were indeed victims of involuntary servitude.

\subsection{Child Labor Trafficking Today}

\subsubsection{United States Citizen Children}

Forced peddling, as in the Ancarola case, is no exception in modern-day America. Labor traffickers often tar- get homeless youth because they lack access to shelter, food, and personal connections (Gibbs et al., 2015). Often promises of paid, legitimate employment are not realized. A survey conducted by the National Network for Youth (2015) found that door-to-door trafficking sales rings had targeted runaway and homeless youth. These youth were lured by the promise of housing, employment, and food, but found themselves living in overcrowded motel rooms with other labor-trafficked youth, receiving little or no pay, and given unreasonable sales quotas. For example, in 2011, 24 children and young adults were lured to Orlando, Florida, with promises of honest wages. Instead, they were crammed into the back of a van, driven around, and forced to sell cheap items and candy bars door-to-door and outside of gas stations. They worked 10-hour days and were transported in unsafe conditions to unfamiliar neighborhoods. Their exploiters rationed their food and water. Police ultimately arrested two men in connection with this operation on labor trafficking charges (Gallup, 2013). Local human rights activists and the Polaris Project, a national nongovernmental organization running the NHTRC, state these sales crews targeting young people are a growing regional trend (Center for the Advancement of Human Rights, 2010). Research has demonstrated that begging networks may conceal labor trafficking and exploit runaway youth, foster care youth, and other vulnerable populations also at risk of sex trafficking (Dank, 2011). In 2014 , of the $9 \%$ of the reported cases to NHTRC involving child labor trafficking, the top forms of labor trafficking were (1) traveling sales crew, (2) begging, and (3) peddling (Polaris Project, 2015).

\subsubsection{Children Who Are Not United States Citizens}

In addition to cases involving United States citizen children engaged in forced and coerced labor, foreign-born and undocumented children are also subject to involuntary servitude, debt bondage and peonage. In 2014, $66 \%$ of child victims who received "eligibility letters" by the federal government as potential or confirmed child trafficking victims were labor trafficking victims (Attorney General, 2014). These cases include children being forced into domestic servitude as nannies or housekeepers, forced labor in agriculture, work in restaurants and factories. Some children enter the United States legally, others with fraudulent visas, and others are unauthorized. For example, in United States v. Udeozor (2008), a woman and her husband brought a 14-year-old child from Nigeria to the United States using their daughter's passport. They were subsequently convicted of involuntary servitude after recruiting and retaining the Nigerian girl as a house slave, where she was a victim of forced labor and repeated physical, psychological, and sexual abuse and assault for four years.

Unaccompanied immigrant children arriving at the United States border are another vulnerable population to labor trafficking. After a surge in 2014, and a brief drop 
in arrivals in 2015, the number of immigrant children increased again until the second quarter of 2017 (US Administration for Children and Families, 2017). Often, unaccompanied children become victims of labor trafficking after the child or the child's family incur a large debt to cover the cost of their passage to the United States (Loyola University Chicago, 2016). What starts out as smuggling quickly becomes labor trafficking when debt falls to the child to repay. The child may be forced to work off his or her debt in restaurants, agriculture, construction, domestic work, manufacturing, or criminal acts at the hands of drug cartels and gangs-jobs that are dangerous, isolated, and highly exploitative. In some cases, these children are criminalized for acts they were forced to perform by their traffickers, including drug sales and smuggling (Montalvo, 2012).

Another example of labor trafficking of foreign-born youth comes via competitive sports. In 2015, the Department of Homeland Security raided the Faith Baptist Christian Academy South in Ludowici, Georgia, and discovered thirty young boys, mostly Dominican, who had been living in the campus gym since 2013 and sleeping on the floor. The boys had been recruited to America with the promise of a high school education and a college scholarship (Harper, 2015). In another similar case, four teenage basketball players from Nigeria were lured to the United States with the promise of college scholarships to play basketball. One boy ended up homeless in New York City, while the other three children were placed in foster care in Michigan (Harper, 2016).

Recent research suggests that trafficked children have suffered higher incidents of neglect and of physical and sexual abuse prior to the trafficking. In one study, at least one-third of young people receiving services as trafficking victims had been previously involved in the child welfare system and nearly two-thirds of one nongovernmental clients had been involved in the juvenile justice system (Gibbs et al., 2015). This research should be explored to determine the social determinates and context that can affect a child's vulnerability. A history of abuse or neglect, limited or lack of access to education, economic security and employment, positive social networks, health, safety, and housing are often precursors to subsequent exploitation and human trafficking.

Another risk factor emerging in the literature is homelessness. A recent study surveying over 600 homeless youth in the United States and Canada reports that nearly one in five homeless youth were or are victims of either sex or labor trafficking, and in some cases, both (Loyola University New Orleans, 2016). 8\% of the respondents identified as being trafficked for labor, with the majority (81\%) reporting forced drug sales. The drug sales occurred both by familial networks and coercion as well as organized crime and gang activity. Runaway and homeless youth are at high-risk to both labor and sex trafficking due to their age, likely history of trauma, displaced living situations, and lack of access to support networks. Many have limited means to forms of employment and economic security, and are often duped into exploitative work after being promised a legitimate job.

These cases of identified child labor trafficking in the United States, both historical and contemporary, also demonstrates that there is much diversity in how labor trafficking manifests itself, and that there is no single child labor trafficking "profile" of a victim or a perpetrator. Trafficked minors include young children and adolescents; children of any race and culture; United States citizen and non-United States citizen; children traveling to the United States alone, and those accompanied by their family; boys and girls.

\section{Limitations of Efforts to Combat Child Labor Trafficking}

Despite evidence of child labor trafficking occurring in the United States, efforts to both identify and prevent child labor trafficking victims continue to be stymied for a variety of three intersectional reasons: lack of research and data collection, legislation and policies prioritizing sex trafficking, and lack of proper training of first responders and child serving organizations, leading to ineffective operational responses to identify such cases. These issues are not singular, and as demonstrated below, often intersect with one another.

\subsection{Limitations of the Research}

Effective data collection is critical in advancing the policy intentions of federal anti-trafficking laws and efforts to protect children from exploitation. Good data creates research-informed policies and improved services for children who are victims of child trafficking. While there have been modest improvements in data collection measures for child trafficking since the passage of the TVPA, these efforts are primarily focused on sex trafficking. Furthermore, at present, few methodologically rigorous, empirically-based research studies concerning labor trafficking exist, as most focus exclusively on child sex trafficking. Quantitative data or measures of child labor trafficking prevalence and characteristics in the United States are very limited. It mostly exists via three forms: (a) Prosecutions of forced labor or involuntary servitude cases (which often do not disaggregate information between adults and children), (b) NHTRC tips or cases reported, (c) letters of eligibility (for humanitarian benefits and services) issued by federal authorities to foreign national children who are potential or confirmed cases of human (labor or sex) trafficking, and the case files associated with the youth provided letters of eligibly for services (which are limited only to foreign national children), and service provider data and case files. To date, there has been only one study solely addressing child labor trafficking in the United States by anthropologist, Elzbieta Godziak (Gozdziak \& Bump, 2008). The study is almost 10 years old, with primary data limited to the experiences of 17 survivors and 26 key informants. The re- 
search methods included review of the child's case files and interviews with service providers working with the trafficked youth.

Important progress has been made to document labor trafficking in the United States, but it continues to largely focus on adults. The Urban Institute's major research report on labor trafficking reviewed a sample of 122 closed labor trafficking victim service records from service providers in four United States cities, but the majority were adults (Owens et al., 2014). The National Institute of Justice also supported research on this topic, showing that approximately $30 \%$ of migrant workers in San Diego were exploited for labor, but this research also exclusively focused on the experiences of adults ( $\mathrm{Na}$ tional Institute of Justice, 2013).

Part of the problem is the lack of data sets distinguishing children from adults, as well as child labor trafficking from sex trafficking. In the most recent Federal Strategic Action Plan on Services for Victims of Human Trafficking in the United States (2013-2017), the United States government recognized the lack of data on services for child trafficking victims and called for research to establish baseline knowledge of human trafficking and victim services. The Department of Health and Human Services (HHS) has launched a multi-year initiative to standardize human trafficking data and to integrate questions on both commercial sexual exploitation and forced labor into the Runaway and Homeless Youth Management Information System, which is a promising initiative that may create better data on child labor trafficking. The Federal Strategic Action Plan on Services for Victims of Human Trafficking in the United States (2013-2017) created an action plan to study the prevalence of commercial sexual exploitation of children in the United States, but notably did not create a parallel action plan related to labor trafficking of children. Rather, as indicated earlier, the labor trafficking research initiatives continued to focus predominately on adults (Owens et al., 2014).

One example of how to better gather quantitative data on child labor trafficking is creating a mechanism to formally collect such data, not just in criminal justice systems, but public child serving systems such as child protection. In the state of Illinois, the Illinois Safe Children's Act (2010), amended the Illinois Abused and Neglected Child Reporting Act (ANCRA, 1975), which defines intake and investigation of child abuse and neglect reports within the state of Illinois to include an allegation of "human trafficking of children" as defined under the TVPA and the Illinois anti-trafficking legislation. It combines both sex and labor trafficking as a form of child abuse and neglect. This allegation of human trafficking (“\#40/\#90") defines abuse via allegation \#40, including labor exploitation, commercial sexual exploitation, the production of pornography or sexually explicit performance. The second, allegation \#90, includes incidents involving neglect or any blatant disregard of a caregiver's responsibility that results in a child being trafficked (Illinois Department of Children and Family Ser- vices, 2015). Incidents of allegations \#40/\#90 are captured in a statewide databased, and available via the Child Abuse and Neglect Tracking System (CANTS) in Illinois. This crucial measure-the creation of a child abuse and neglect allegation via the state child protection system-provides for the possibility of conducting important research on the prevalence and characteristics of investigated allegations of child trafficking, including child labor trafficking, within a state (Havlicek, Huston, Boughton, \& Zhang, 2016).

Because human trafficking is defined as a specific form of child maltreatment in the Illinois child protection system, it becomes possible to identify and describe investigated allegations of human trafficking in Illinois. A recent study, and currently the only one of its kind, used administrative data from the Illinois Department of Children and Families Services (DCFS) to compare the prevalence of investigated allegations of human trafficking (Havlicek et al., 2016). The study shows that between 2012-1015, 41\% of children with at least one investigated allegation of maltreatment prior to allegation of human trafficking have an allegation of sexual abuse, and $52 \%$ have an allegation of physical abuse, with multiple types of maltreatment in case records preceding an allegation of human trafficking. The study suggest that more than one out of four children in the study with an investigated allegation of human trafficking had an entry in out-of-home care. This demonstrates that most of the children who had an investigation of child trafficking in Illinois experienced multiple forms of abuse and neglect prior to being trafficked, and that children placed in foster or residential care facilities face higher risk of being trafficked.

There are clearly limitations to this approach. First, it still does not disaggregate child labor and sex trafficking, and combines them both. A study that relies solely on the number of investigated allegations of sex and labor trafficking in one state has significant limitations for broader conclusions, However, the possibilities of further study and analysis of this population using this particular model are profound. The fact that labor trafficking was included in the data collection is a crucial first step. Additionally, if we know that certain patterns of abuse (or abusers) put children at higher risk of human trafficking, more effective and targeted prevention and intervention measures can be explored. Without such data, and specifically data on both child labor and sex trafficking, this is not possible. The Illinois data could be even more improved if it distinguished sex trafficking from labor trafficking to better understand any differences or similarities of the prevalence and characteristics of each form of human trafficking. More states should explore similar avenues of collecting data on both the prevalence and analysis of child sex and labor trafficking interactions with state child protection systems. This can be done by incorporating data collection measures in state anti-trafficking laws, exploring existing data collection measures by public (and private) child serving systems, and using Illinois' 
case example, amending state level child abuse and neglect laws to include both child sex and labor trafficking, triggering a new data set to better inform research, policies, and practices related to child trafficking.

\subsection{Limitations of Current Legis/ation and Policy}

The academic and governmental research focus on sex trafficking is paralleled in legislation and policy intended to identify and serve child victims of human trafficking. Since the passage of the TVPA, subsequent legislation on both state and federal levels to combat trafficking measures fail to recognize child labor trafficking. While most legislation refers to "human trafficking" more broadlywhich should include both labor and sex trafficking of all persons, adults and children-in practice, use of this broader term relegates child trafficking to a subset of human trafficking whereby the children who are trafficked for labor remain hidden and invisible. Additionally, data collection mandated by laws and policies addressing human trafficking more broadly also fail to acknowledge the need for improved data collection on forced labor and child labor trafficking. For example, the Preventing Sex Trafficking and Strengthening Families Act (2014) mandates that child welfare agencies report the numbers of children in their care, placement, or supervision who are identified as sex trafficking victims to the HHS (Preventing Sex Trafficking and Strengthening Families Act, 2014). This is groundbreaking legislation that mandates every child protection agency in the country to better identify and collect data on child trafficking, but focuses exclusively on sex trafficking. Similarly, the Justice for Victims of Trafficking Act, which seeks creates additional protections child victims, amends the Child Abuse Prevention and Treatment Act to include provisions to identify and assess "known or suspected victims of sex trafficking" (Justice for Victims of Trafficking Act, 2015). While these provisions are positive steps in the broader anti-trafficking movement to continue to develop data collection tools, procedures, and policies to identify and respond to child sex trafficking in the United States, they virtually ignore child labor trafficking. They also miss opportunities to create important data collection mechanisms for child labor trafficking.

While the TVPA and its subsequent reauthorizations prohibit labor trafficking and forced labor, efforts to prosecute these crimes by local governments and states are still deficient. State-level policies, including Safe Harbor laws currently in over 20 states, decriminalize juvenile prostitution, allow some prior sentences to be vacated, and amend the definition of child abuse to include child trafficking (Polaris Project, 2015). While these are promising measures to improve identification and intervention services for child sex trafficking victims, including creating opportunities to collect data on the prevalence and response to sex trafficking of minors, these laws have no impact for children who are victims of forced labor or labor trafficking. Almost all of these Safe Har- bor laws provide protections only for sexually exploited youth, while children engaged in forced labor and labor trafficking remain unidentified and vulnerable to penalties (e.g., for peddling, engaging in forced criminality, or working while unauthorized or undocumented), detention, and further trauma. States should consider the Illinois model, by using their Safe Harbor statutes to protect children who are victims of both labor and sex trafficking, and to amend child protection statutes to create datasets to better understand the dynamics of both child labor and sex trafficking.

\subsection{Limitations of Current Labor Laws}

Documented case examples of child labor trafficking indicate that industries and businesses that traditionally hire children and youth can be improved to protect children and to provide a way for children in need to seek assistance. For example, child labor standards in agriculture can be improved to prevent the sale of children for the purpose of forced labor and labor trafficking (Loyola University Chicago, 2016). Outside of agriculture, the standard minimum age for work is 16 . There are no similar restrictions protecting children working in agriculture. In agriculture, employers may hire children ages 14 and 15 to work unlimited hours outside of school, with no parental consent requirement (Loyola University Chicago, 2016). While protecting child farmworkers from dangerous and exploitative work is the responsibility the Department of Labor (DOL) and the Environmental Protection Agency, there is, however, currently no specific budget line to support DOL child labor law enforcement (Bureau of Democracy, Human Rights, and Labor, 2016). Without adequate monitoring and enforcement, children are at greater risk of labor exploitation and possibly labor trafficking.

In addition to increasing regulation and monitoring of child labor in the agriculture industry, further examination of corporations' abuse of the J-1 visa program, which was designed to foster cultural exchange and to provide technical training opportunities for foreign college-age students, is needed. Employers do not have to pay payroll taxes on J-1 workers, leading some employers to treat the program as a source of easily exploitable and cheap labor. In one instance, two sisters from the Dominican Republic who were recruited to work in customer service at a luxurious Tennessee hotel found themselves living in the hotel's stables, caring for the horses as well as tending to guest rooms. Their sponsor refused to approve their requests to work elsewhere. Indebted and isolated, they felt that they had no option other than to leave and seek work elsewhere, thereby jeopardizing their J-1 status (Loyola University Chicago, 2016; Southern Poverty Law Center, 2014). This is just one case example of several other documented cases abusing the J-1 program in the United States. More regular monitoring, investigations, and audits could limit the systemic abuse of this program. 


\subsection{Limitations of Criminal Justice and Immigration Systems}

While research on labor trafficking - for both adults and children -in the United States is still limited, the seminal study on this topic, Understanding the Organization, $O p$ eration, and Victimization Process of Labor Trafficking in the United States, concludes that labor trafficking cases are "not prioritized" by both local or federal law enforcement in the United States (Owens et al., 2014). The study notes that many law enforcement agents, particularly local law enforcement, have limited knowledge of the statutory framework for forced labor. Training for law enforcement continues to emphasize sex trafficking, which leads to continued misidentification or lack of identification of labor trafficking of both adults and children.

Prosecutors have narrowly interpreted the TVPA and the TVPRA-and consequently left several categories of victims of forced labor at risk of exploitation and unable to access protections afforded to them as victims of such crimes. Whereas child victims of sex trafficking are not required to prove they were compelled in any way to perform a commercial sex act, victims of child labor trafficking under federal and state statutes must prove "force, fraud, or coercion," with the burden of proof resting with the child. A number of factors inhibit identification of such cases: both a child's fear of deportation, the effects of severe trauma, or being expressly coached to deny any foul play may prevent him or her from being forthcoming with government officials. In some cases, a child may not even know he or she has been trafficked until after being released from custody to the traffickers. In other cases, familial piety or deference to adults may make a show of "force" or "coercion" more challenging, particularly as these terms assume a certain level of agency children may not have. To put another way, children, because they are children often do what adults ask them to do.

Furthermore, current anti-trafficking laws do not distinguish children from adults in the context of labor trafficking. A 12-year-old child must submit evidence and prove eligibility for protection in the same manner as a 30-year-old adult. Developmentally, children are presumed less likely to have the ability to identify and evaluate their options; a child may only be able to identify one option in a situation where an adult would be able to identify multiple options (Beyer, 2000). Also, "because adolescents tend to discount the future and weigh more heavily the short-term risks and benefits, they may experience heightened pressure from the immediate coercion they face" (Conn v. Heinemann, 2007). Therefore, the requirement that child labor trafficking victims prove force, fraud, or coercion-as an adult would-fails to recognize that a child is likely to perceive and react to situations differently than an adult. Research from the fields of child development, child psychology, and anthropology, among other disciplines, should inform better practices to approach child labor trafficking cases from a developmentally and culturally informed perspective to demonstrate how "coercion" or "force" may play out differently with a 7-, 12-, or 16-year-old versus an adult. Simply put, a child may follow a "rule" or order by an adult just because an adult told them to. Requiring child victims of labor trafficking to prove that these statutory elements on par with an adult in order to receive protection inevitably makes protection very difficult to obtain especially when the trafficking experience may not conform to the most traditional model.

Moreover, most unaccompanied immigrant children lack legal representation in the immigration process and once released, they receive little assistance and have access to few resources. As a result, these children risk reentry into the abusive cycle of labor trafficking upon release from custody (VanSickle, 2016). Without legal representation, many unaccompanied immigrant children struggle to obtain protection under the law. When invoked, the TVPA and TVPRA provide several protections under the law. These protections include eligibility for short term immigration relief, including parole and continued presence, and longer term immigration relief, including a T-nonimmigrant Visa which allows trafficking victims to stay in the United States if they would suffer "extreme hardship involving unusual and severe harm" if returned to their home country (Victims of Trafficking and Violence Protection Act, 2000).

\subsection{Limitations of Current Training Models}

Emerging research demonstrates that child labor trafficking victims often encounter at least one, if not several, systems that fail to identify them as victims of child trafficking (Gibbs et al., 2015). These systems include local, state, and federal law enforcement, child welfare and child protection, juvenile justice, education, and social service providers (Covenant House, 2013). The research in the state of Illinois, for example, shows that children with allegations of child trafficking experienced at least four previous encounters with the child welfare system (Havelich, 2016). While the United States government has increased training efforts addressing child trafficking to a larger cohort of first responders and stakeholders since the passage of the TVPA (e.g. Bureau of Democracy, Human Rights, and Labor, 2016), very few training efforts include content addressing both sex and labor trafficking and forced labor of children. Many trainings targeting first responders and researchers continue to refer to victims of "human trafficking" generically but provide case examples that emphasize sex trafficking, or just focus exclusively on sex trafficking, and often use case examples of adults. Very few address the needs of children or address child labor trafficking at all.

This lack of training or misinformation about child trafficking significantly impacts the ability to identify and respond to child labor trafficking cases (Farrell et al., 2012). Most law enforcement, particularly local law enforcement, do not have the knowledge or capacity to identify labor trafficking (Farrell et al., 2012). Most in- 
vestigatory or specialized units dedicated to responding to human trafficking have foundational training in vice (or sex crimes), which limit their abilities to identify and respond to labor trafficking cases. Moreover, most law enforcement agents have challenges in defining federal anti-trafficking laws, and experience challenges discerning when "hard work" becomes a labor violation or labor trafficking (Owens et al., 2014). This has profound impact not just on victim identification, but also on data collection by critical first responders.

\section{Conclusion}

The phenomenon known as involuntary servitude, slavery, and more recently, "labor trafficking," is unfortunately not new in the United States or throughout the world. While there continue to be new criminal statutes, laws, and policies promulgated to address this crime, child labor trafficking continues to persist with little efforts to identify, respond to, and build critical knowledge of this crime. Data collection measures under current anti-trafficking legislation, as well as existing intake systems by child welfare and law enforcement agencies, rarely include child labor trafficking. Without more mechanisms in place to conduct better data collection and research, efforts to understand both the prevalence and characteristics of child labor trafficking in the United States will continue to be hindered. Training curricula and programs currently lack sufficient data, knowledge, and identification practices to inform first responders to identify and respond to child labor trafficking cases. This impacts the ability to conduct empirically based research on the prevalence and characters of the problem, as well as how to respond to and protect survivors of child labor trafficking.

All public and private agencies collecting antitrafficking data, particularly those serving vulnerable youth, should be reviewing their intake procedures and data collection measures to ensure child labor trafficking data is collected alongside child sex trafficking. All existing and future policies and legislation purporting to better respond to child trafficking should be reviewed to ensure that the definition of human trafficking explicitly includes both labor and sex trafficking, Moreover, policies should consider how to incorporate mechanisms for systems and providers to identify, collect data, and build capacity to respond to both child sex and labor trafficking. This could include the example of the state of Illinois, where the child abuse and neglect statutes include both labor and sex trafficking as a form of abuse and neglect, which is collected as part of a statewide database. Training curricula should be vetted by both law enforcement and non-governmental experts with experience with child labor trafficking cases to develop more sophisticated and accurate curricula and educational materials describing incidents of child labor trafficking. Local law enforcement, especially, needs better training on how to identify and investigate these cases, particu- larly as they are often the first responders in the community. Both governmental and civil society stakeholder should ensure that when public awareness, outreach, training, capacity building, or policy efforts are made to address child trafficking, both labor and sex trafficking are emphasized. Otherwise, the efforts to protect the most vulnerable members of our society will continue to be stymied.

\section{Acknowledgements}

The purpose of this article is to emphasize the importance of improving efforts to address both labor and sexual exploitation of all children, regardless of nationality or legal status, in advancing the policy intentions of United States anti-trafficking laws, and to specifically highlight the deficiencies of United States anti-trafficking efforts to combat child labor trafficking. Survivors of both labor and sexual trafficking face many of the same challenges, and neither should be prioritized as a matter of policy or implementation. I would like to acknowledge the important work NGOs, academic centers, service providers, and advocates who work with or on behalf of children who are victims of both sex and forced labor. I wish to thank my colleagues Maria Woltjen and Kelly Kribs of the Young Center for Immigrant Children's Rights at the University of Chicago. Their work and advocacy on issues of unaccompanied minors has informed my research and writing on this topic. I also wish to extend my gratitude to my Graduate Assistant, Dorothy McLeod, for her excellent research and editing assistance. Finally, I wish to thank my own children, Maeve and Mason, who's love and presence are a daily reminder of the importance to protect children's rights.

\section{Conflict of Interests}

The author declares no conflict of interests.

\section{References}

Attorney General. (2014). Attorney General's annual report to Congress and assessment of US Government activities to combat trafficking in persons, fiscal year 2014. Retrieved from https://www.justice.gov/ humantrafficking/file/797606/download

Banks, D., \& Kyckelhahn, T. (2011). Characteristics of suspected human trafficking incidents, 2008-2010. Washington, DC: US Department of Justice, Bureau of Justice Statistics.

Beyer, M. (2000). Immaturity, culpability, \& competency in juveniles: A study of L17 cases. Criminal Justice, 15(2), 27-40.

Bureau of Democracy, Human Rights, and Labor. (2016). Combined third and fourth periodic report of the U.S. on the optional protocols to the Convention on the Rights of the Child on the involvement of children in armed conflict and the sale of children, 
child prostitution, and child pornography. Washington, DC: U.S. Department of State. Retrieved from https://www.state.gov/j/drl/rls/252299.html

Center for the Advancement of Human Rights. (2010). Florida strategic plan on human trafficking. Florida State University.

Conn v. Heinemann, No. 920A.2d 278 (Conn. Sup. Ct. 2007).

Covenant House. (2013). Homelessness, survival sex, and human trafficking: As experienced by the youth of Covenant House New York. New York, NY. Retrieved from https://d28whvbyjonrpc.cloudfront.net/s3fspublic/attachments/Covenant-House-trafficking-stu dy.pdf

Dank, Meredith. (2011). The lost children of New York City: Population estimate, network attributes and the role of social capital in the commercial sexual exploitation of children in New York City (PhD Dissertation). City University of New York.

Farrell, A., McDevitt, J., Pfeffer, R., Fahy, S., Owens, C., Dank, M., \& Adams, W. (2012). Identifying challenges to improve the investigation and proescution of state and local human trafficking cases. Washington, DC: National Institute of Justice.

Finklea, K., Fernandes-Alcantara, A. L., \& Siskin, A. (2015). Sex trafficking of children in the United States: Overview and issues for congress. Washington, DC: Congressional Research Service.

Gallup, J. D. (2013). Police say 24 children rescued from human trafficking scheme. Florida Today. Retrieved from http://www.floridatoday.com/story/news/loc al/2013/10/29/police-say-24-children-rescued-from -human-trafficking-scheme-two/77199404

Gibbs, D., Hardison Walters, J. L., Lutnick, A., Miller, S., \& Kulckman, M. (2015). Evaluation of services for domestic minor victims of human trafficking (submitted to the U.S. Department of Justice). Retrieved from https://www.ncjrs.gov/pdffiles1/nij/grants/ 248578.pdf

Goodey, J. (2008). Human trafficking: Sketchy data and policy responses. Criminology \& Criminal Justice, 8(4), 421-442. https://doi.org/10.1177/174889580 8096471

Gozdziak, E., \& Bump, M. N. (2008). Victims no longer: Research on child survivors of trafficking for sexual and labor exploitations in the United States (submitted to the U.S. Department of Justice). Retrieved from https://www.ncjrs.gov/pdffiles1/nij/grants/ 221891.pdf

Harper, A. (2015). A lesser-known human trafficking problems: Teenage basketball players. NPR Code Switch. Retrieved from http://www.npr.org/ sections/codeswitch/2015/04/06/397822833/a-less er-known-human-trafficking-problem-teenage-bask etball-players

Harper, A. (2016). How elite basketball exploits African athletes. Harper's Magazine. Retrieved from http:// harpers.org/archive/2015/04/american-hustle
Havlicek, J., Huston, S., Boughton, S., \& Zhang, S. (2016). Human trafficking of children in Illinois: Prevalence and characteristics. Children and Youth Services Review, 69, 127-135. https://doi.org/10.1016/ j.childyouth.2016.08.010

Illinois Abused and Neglected Child Reporting Act. (1975). Retrieved from http://www.ilga.gov/legislation/ilcs /ilcs3.asp?ActID=1460\&ChapterID=32

Illinois Department of Children and Family Services. (2015). Reports of child abuse and neglect (Appendix B). Springfield, IL.

Illinois Safe Children's Act. (2010). Retrieved from http://www.ilga.gov/legislation/publicacts/96/0961464.htm

Justice for Victims of Trafficking Act, Pub. L. No. 227, 129 U.S. Code (2015). Retrieved from https://www.con gress.gov/114/plaws/publ22/PLAW-114publ22.pdf

Loyola University Chicago. (2016). Alternative report. An NGO response to the periodic report of the United States of America to the UN Committee on the Rights of the Child concerning the optional protocol to the convention on the rights of the child on the sale of children, child prostitution and child pornography. Chicago, IL. Retrieved from http://www.luc.edu/ media/lucedu/chrc/pdfs/OPSC\%20Alternative\%20 Report.pdf

Loyola University New Orleans. (2016). Labor and sex trafficking among homeless youth: A ten-city executive summary. New York, NY: Covenant House. Retrieved from https://www.covenanthouse.org/land ing/trafficking/docs/Loyola-Research-Results.pdf

Mintz, S. (2006). Huck's raft: A history of American childhood. Belknap Press.

Montalvo, T. L. (2012). Children in Mexico: Criminals or victims? CNN. Retrieved from http:// www.cnn.com/2012/01/17/world/americas/mexicochildren-crime/index.html

National Institute of Justice. (2013). Thirty percent of migrant laborers in San Diego experience trafficking violations (In Short). Washington, DC: US Department of Justice. Retrieved from https:// www.ncjrs.gov/pdffiles1/nij/242955.pdf

National Network for Youth. (2015). What works to end youth homelessness? Washington, DC. Retrieved from https://www.nn4youth.org/wp-content/uploa ds/2015-What-Works-to-End-Youth-Homlessness.pdf

Owens, C., Dank, M., Breaux, J., Banuelos, I., Farrell, A., Pfeffer, R., . . McDevitt, J. (2014). Understanding the organization, operation, and victimization process of labor trafficking in the United States (Research Report). Washington, DC: Urban Institute. Retrieved from http://www.urban.org/research/pub lication/understanding-organization-operation-andvictimization-process-labor-trafficking-united-states

United Nations Convention against Transnational Organized Crime. (2000). Protocol to prevent, suppress and punish trafficking in persons especially women and children. Retrieved from http://www.ohchr.org/ 
EN/Professionallnterest/Pages/ProtocolTraffickingIn Persons.aspx

Polaris Project. (2015). Child trafficking and the child welfare system. Retrieved from https://polarisproject. org/sites/default/files/Child\%20Welfare\%20Fact\%20 Sheet.pdf

Preventing Sex Trafficking and Strengthening Families Act, Pub. L. No. 1919, 128 U.S. Code (2014). Retrieved from https://www.congress.gov/113/plaws/ publ183/PLAW-113publ183.pdf

Sale into Involuntary Servitude, Pub. L. No. 1584 (formerly No. 446), 18 U.S. Code (1948). Retrieved from https://www.law.cornell.edu/uscode/text/18/1584

Southern Poverty Law Center. (2014). Culture shock: The exploitation of J-1 cultural exchange workers. Mongomery, AL. Retrieved from https://www. splcenter.org/20140202/culture-shock-exploitationj-1-cultural-exchange-workers

Stransky, M., \& Finkelhor, D. (2008). Sex trafficking of minors: How many juveniles are being prostituted in the US? Durham, NH: Crimes against Children Research Center.

Trafficking Victims Protection Reauthorization Act of 2003. (2003). Retrieved from https://www.state.gov/ $\mathrm{j} /$ tip/laws/61130.htm

Trafficking Victims Protection Reauthorization Act of 2005. (2005). Retrieved from https://www.state.gov/ j/tip/laws/61106.htm
Trafficking Victims Protection Reauthorization Act of 2013. (2013). Retrieved from https://www.congress. gov/bill/113th-congress/house-bill/898

United States V. Ancarola, No. 1 F (Circuit Court, S. D. New York 1880).

United States V. Lewis, No. 797F.2d358 (US Court of Appeals, Seventh District 1986). Retrieved from http://openjurist.org/797/f2d/358/united-states-vlewis

United States V. Udeozor, No. 515F.3d260 (US Court of Appeals, Fourth District 2008). Retrieved from https://scholar.google.com/scholar_case?case $=5845$ 659249981150854\&hl=en\&as_sdt=6\&as_vis=1\&oi= scholarr

US Administration for Children and Families. (2017). ACF fact sheet. Washington, DC: Office on Trafficking in Persons. Retrieved from https://www.acf.hhs.gov/ sites/default/files/assets/2017factsheets_otip.pdf

VanSickle, A. (2016). Overwhelmed federal officials released immigrant teens to traffickers in 2014. Washington Post. Retrieved from https://www. washingtonpost.com/national/failures-in-handlingunaccompanied-migrant-minors-have-led-to-traffick ing/2016/01/26/c47de164-c138-11e5-9443-7074c3 645405_story.html

William Wilberforce Trafficking Victims Protection Reauthorization Act of 2008. (2008). Retrieved from https://www.state.gov/j/tip/laws/113178.htm

\section{About the Author}

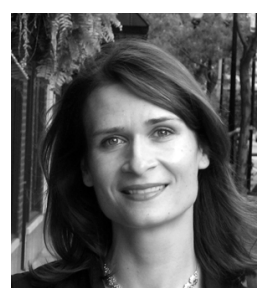

Katherine Kaufka Walts is the Director of the Center for the Human Rights of Children at Loyola University Chicago. As part of her work, Ms. Kaufka Walts conducts research and provides technical assistance, training and consultation to various stakeholders in the United States and internationally on various topics, including child trafficking and children's rights issues. Prior to Loyola, she provided successful legal representation of survivors of both sex and labor trafficking under criminal justice and immigration proceedings. 